\title{
Application of RFID combined with blockchain technology in logistics of construction materials
}

\author{
A. Lanko $^{1 *}, N$. Vatin $^{1}$ and $A$. Kaklauskas ${ }^{2}$ \\ ${ }^{1}$ Peter the Great St.Petersburg Polytechnic University, Polytechnicheskaya, 29, St. Petersburg, 195251, \\ Russia \\ ${ }^{2}$ Vilniaus Gedimino technikos universitetas, Vilnius, Lithuania
}

\begin{abstract}
Nowadays, almost none of the fields of human activity can do without supply chain management. In addition, implementation of one in construction companies contributes to major economic benefits. The article considers the application feasibility of blockchain in logistics of construction materials through the usage of RFID technology. An example of introduction to the process of manufacturing and delivery of ready-mixed concrete is given. The main advantages, shortcomings, perspectives, as well as difficulties arising in the implementation of blockchain technology in the construction industry are described. Special attention is paid to the applicability of these technologies.
\end{abstract}

\section{Introduction}

In the current business relationships, a significant part of the cost savings depends on the possibility and ability of the customer to manage supplies [1-4]. The application of the main methods of supply logistics [5], [6], allows to reduce the financial losses and, consequently, to increase the profit. Minimization (optimization) of expenses is an indispensable condition for organizing the management of the construction process [7] and is important for creating a competitive price of the final product [8], [9]. Losses arise due to the downtime caused by the lack of necessary building materials, equipment or components at a certain point or vice versa due to the long-term storage of materials, that are not currently needed, at the company warehouses [10], [11], [12]. On the other hand, losses can arise due to overcharged delivery, that results from illiterate supply logistics, or failure to choose the right carrier. Competent supply chain management consists in reliable and high-quality provision of production units with the material resources that are necessary to fulfill a given production plan.

The transition of the supply chain in the construction industry to the blockchain system allows making a technological breakthrough in the logistics by creating a transparent system of interaction between all participants. A decentralized logistics system based on smart contracts will help all participants to gain measurable benefits and a unique transparent economic environment, as well as it will ensure complete security of the entire supply chain. The functionality of the system allows to protect cargo owners and carriers, eliminate problems of trust between participants, remove information barriers and avoid suit costs.

\footnotetext{
* Corresponding author: alexandr.lancko@yandex.ru
} 


\section{Core terminology and concepts}

\subsection{Blockchain}

Simplistically, the blockchain can be presented as a large distributed database, which has the following significant differences from the "traditional" widely used in our time arrays of information:

- storage of the database for all participants of the system, in the form of interconnected copies;

- the data does not exist separately from each other, but it is linked into a continuous chain of blocks in a way that each new data block refers to the previous one, which practically excludes data forgery in any block;

- one of the most reliable cryptographic methods is used - hashing or hash functions to protect data;

- As a rule, the blockchain records are open and transparent for all users of the network.

Thus, the blockchain is a kind of an open electronic account book reliably protected from false data, where records are sequentially linked and are stored in identical copies by peers.

\subsection{Transactions}

One of the key concepts of the blockchain is records, called transactions. Blockchain transaction can be characterized as a process when the involved parties acquire or lose a certain status (status of owner, user, etc.). An example of a transaction in the logistics of construction materials can be a record in a blockchain about the shipment of the goods to the receiver or about the production (extraction, processing) of the material.

\subsection{Smart contract}

A smart contract is a built-in program for the automatic execution of actions as a result of the occurrence of certain events. The automatic pay off with the supplier and the carrier of the construction materials after the receipt confirmation can be an example.

\section{Development of digital supply chains}

Before blockchain solutions were implemented, the development of digital supply chains has passed a long way. At the start, large forwarding agents used ERP-systems [13], [14], [15] in order to respond to delivery requests faster. Then the Internet age began, various Internet sites and forums started appearing, which were used for advertising their services, searching for customers or a contractor for transportation orders. Finally, cargo services similar to the UBER passenger transportation platform appeared. The problem with these services is that the customer is offered to rent a whole truck for a small distance, while the transportation of small wares or the multimodal transportation with using several different vehicles is not available at the time of writing the article. In addition, modern centralized platforms cannot completely manage algorithms that are resistant to damage of goods; eliminate the problem of trust between participants.

The commission for intermediary services while performing transportation of construction and related products depends on the complexity and number of transportation modules, and can reach $25 \%$ of the total order amount. The formation of this amount is often not transparent; therefore, the customer does not understand how to reduce the cost of intermediary services. Many of the risks in the logistics industry are coming from the lack of information reliability, centralized systems do not ensure the provision of complete or accurate information. Transition to decentralized services and implementing smart contract and blockchain technologies will ensure a proper level of transparency and credibility in the logistics market at large and the provision of the construction industry particularly. The 
formation of costs, including commissions, will become transparent, which will enable the more efficient supply chain management. The introduction of a global decentralized system will allow significant increase in the efficiency of participants' work in the supply chain, removing unnecessary links, reduce negative consequences from the human factor influence. Besides, the control over the movement of goods will become simpler.

\section{Use of blockchain in supply of ready-mixed concrete}

In some cases, for example, when delivering ready-mixed concrete, it is crucial to monitor the delivery duration. There is a need not only to register the moment of departure of the vehicle carrying concrete from the plant territory accurately, but also to avoid the possibility of data errors due to the "human factor" or intentionally false information. The combination of RFID and blockchain gives such an opportunity. RFID (Radio Frequency IDentification) is a method for automatically identifying objects, which consists in reading or writing data stored in so-called RFID tags with radio signals by RFID scanners. It can pass according to the following scenario.

A passive RFID tag or several tags specially selected for this type of use is placed in the concrete mix when pouring for transportation. The Russian company "Systematika" working out the development under Rosnano state innovation project can be given as an example of producers of such tags. These tags can be put in the slab when pouring concrete into the mold, which will enable monitoring all stages of production and operation of the product, as well as performing quality control. When the concrete mix is being produced, the tag is registered in the blockchain system and the first production transaction is made. The recording format allows making many notes like a concrete grade, the presence of special additives. After the shipment of concrete, a record in the blockchain is made about the transfer of the concrete mix to the carrier, with time recording, which is signed by the electronic keys of the plant representative and the carrier. The transaction is considered to be confirmed and valid after checking its format, the required digital signatures, and recording it into the transaction block along with other transactions [16-18].

Assuming a situation of the global use of blockchain, which is idealistic for today, this tag will contain information on all suppliers of concrete production: the cement producer, quarries for extraction of sand and gravel, manufacturers of various additives. Meanwhile the delivery of all the necessary "ingredients" will be also carried out in the blockchain system within the framework of previous transactions. The unified and distributed system will not allow the manufacturer to use materials that do not meet the standards, as well as "double expense ". In other words, if the manufacturer purchased cement to produce $100 \mathrm{~m}^{3}$ of concrete of a certain grade, he will not be able to unload the more volume of concrete. This transaction will be confirmed by the blockchain. He also will not be able to save part of the cement and sell because he is not a cement producer, and according to the blockchain, all the cement he received has already been consumed for the production of concrete. Moreover, the cement producer can add RFID tags into each package or into parcel when transport in bulk, in order to monitor not only the time and place of its manufacture, but the entire chain of its delivery to the concrete plant, which will reveal the unsuitable conditions of storage or transportation.

Careers and admixture manufacturers can also provide their products with such RFID tags. Therefore, when the output of the plant, the concrete is provided with an RFID tag which will help the purchaser of this product to obtain comprehensive data on the purchased products:

- time and place of concrete production, conditions of its delivery to the construction site, monitoring the route of the vehicle through the satellite;

- reliable composition of concrete; 
- suppliers of all components of concrete, the date of their production, the conditions for their storage and transportation;

- pricing of the whole production chain.

This transparency will help avoiding the use of poor-quality or counterfeit products.

The following figure shows the way the blockchain works (Fig. 1). It presents a simplified chain of movement of all components for making concrete mix from quarries to the construction site. The beginning of our scheme contains:

- quarry for extraction of sand;

- quarry for extraction and processing of gravel;

- complex for the extraction, processing and production of gypsum and clinker for the production of cement;

- two separate complexes for extraction, processing and manufacturing of two conditional additives necessary for the production of the required concrete grade.

To simplify the scheme, all five complexes are assumed to not use components purchased from other subjects. All products sold by them are manufactured locally from local materials.

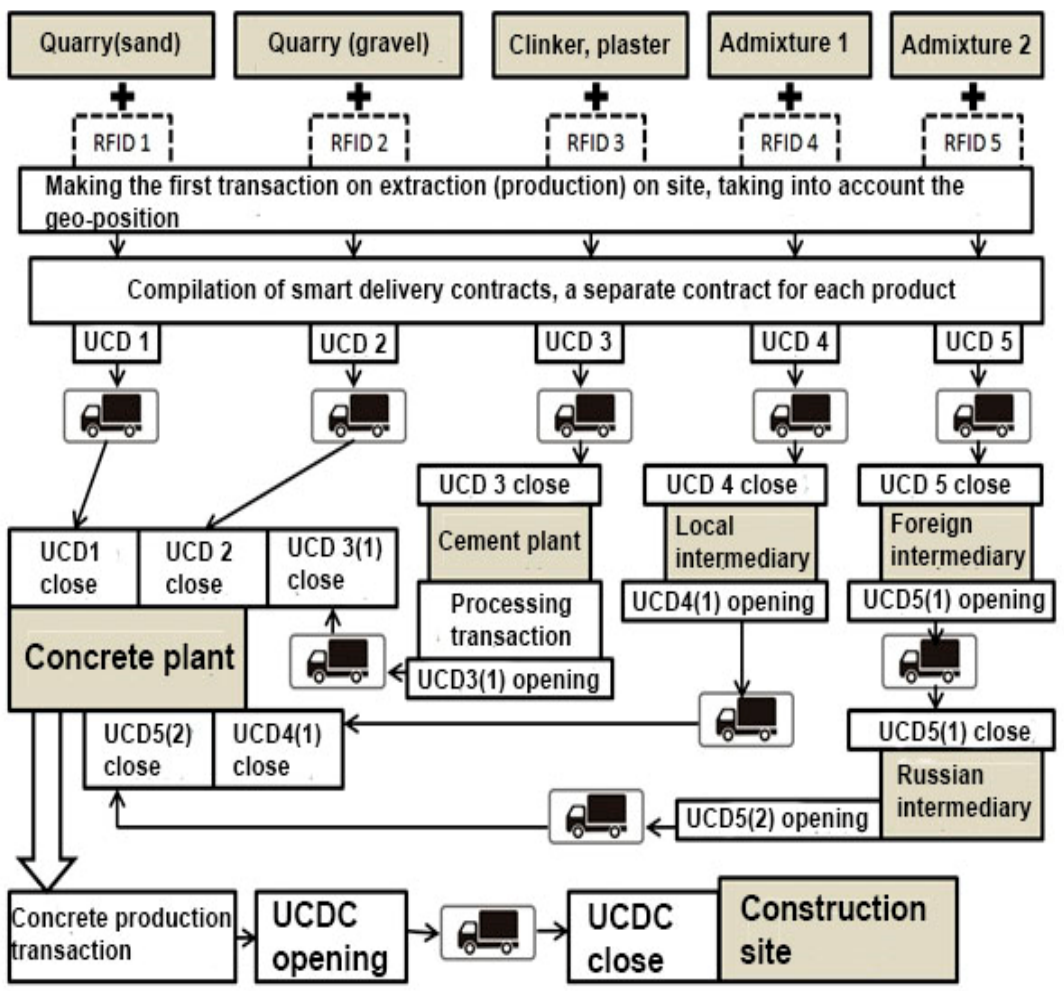

Fig. 1 Complete production and logistics chain of the concrete mix before being delivered to the construction site

The diagram shows the movement and further use of the products of all five complexes.

Careers form lots of sand and gravel in the required quantity on request of a concrete plant. Each lot is accompanied by one or more passive RFID tag. For the convenience of monitoring the movement, one shipment should be divided into several vehicles. If there is a direct visual access to the tag, cheaper technologies, such as QR (Quick Response Code) tags, can also be applied. This "quick response code" is a two-dimensional optical visualization of information and actively replaces the aging bar codes due to the greater information capacity. 
The cheapness of QR-tags and the lack of the need for special equipment for their reading is their certain advantage in comparison with RFID. To scan the QR-code it is enough to have a smartphone with a camera and a special application. QR-tags can be used as duplicates at the initial stage of the implementation of the blockchain in the logistics of construction materials.

Significant limiting of the information capacity, weak protection against forgery and the need for visual contact when reading limit the widespread use of QR technology and make RFID more preferable. RFID tag can completely replace the supporting documents, which are almost impossible to forge. A record about the production is made on the RFID tag (the first transaction is made). In this case, as mentioned above, a number of product information can be included in the transaction. The volume of necessary data is determined by the manufacturer and depends on the necessary accuracy of accounting. The data entered into the transaction will enable fast identifying the place and time of a flaw, prevent various fraudulent fraud related to the substitution or theft of products. If necessary, a function of multi-signature can be added. The meaning of a multi-signature is that one person can not independently make a record in a blockchain. For example, a transaction filled out and signed by the foreman when loading gravel into carriers, is certified by the head of the shipping department with his signature. Thus, there is a double quality and quantity control of the parcel and check for compliance with the product description. In addition, the possibility of recording false information by one of the employees is excluded. After the preparation of the parcel for dispatch, a "smart contract" is made for delivery, which makes accountance automatically between the parties to the transaction when certain events occur in it. In the scheme (Fig. 1), all movement of goods is carried out by independent transport companies. Smart contracts are recorded on existing RFID tags.

\section{Reasonability of implementation}

The first effect from the introduction of RFID tag technologies is a significant acceleration of workflow. Filling and reading of documents can take place in automatic and semiautomatic modes. Technology allows record data on the prepared mix remotely (in motion) on the tag located in the car. Such data as the time of production, exit from the territory of the concrete plant, entry to the site of the customer can be recorded in automatic mode saving time significantly. Automatic or semi-automatic completion of accompanying documents, besides saving time will also reduce the number of employees involved in the process of processing and control. The recoupment from the introduction of this technology in this aspect is calculated individually and depends on the volume of turnover and the corresponding reduction in downtime.

By combining RFID and GLONASS (Global Navigation Satellite System)/GPS technology, it will be possible to track the delivery of ready-mix concrete in real time, which will allow accurately predicting the time of delivery of the products to the customer and optimizing the construction process as much as possible, and minimizing losses from delays in delivery.

The combination of RFID and blockchain technologies will significantly reduce losses from the influence of the human factor and intentionally false information, eliminate the problem of trust between the participants in the turnover. Manufacturers of ready-mixed concrete that have introduced such technologies will be more trusted by the customer, and therefore will have competitive strengths.

The highest possible effect of the introduction of blockchain technology using RFID tags will be observed when creating a single database (exchange) where suppliers and customers of ready-mix concrete can receive actual and reliable data on turnover, place offers and find customers, optimizing the production and use of ready-mixed concrete. 


\section{Conclusion}

Switching of building materials' supply chains, as well as of logistics systems in general, to decentralized accounting seems inevitable due to certain advantages described in the article. It will certainly take a lot of time to create a unified legitimate system based on blockchain or a similar technology. However, the foundation is laid: successful test models between individual corporations have been created. Specialists in the field of logistics coming from different countries actively enter upon exploring the benefits and opportunities of blockchain in logistics and using them, which offers hope for the successful development and widespread implementation of this technology.

\section{References}

1. A.V. Mishakova, A.V. Vakhrushkina, D.R. Anishchenko, Y.A. Tatarkina, Magazine of Civil Engineering, 4, 27-36, doi: 10.18720/MCE.72.2 (2017)

2. D. Ivanov, B. Sokolov Springer. ISBN 978-1-84882-951-0 (2010)

3. S.V. Bovteev, S.V. Kanyukova. Magazine of Civil Engineering, 2, 102-112 doi: 10.5862/MCE.62.10 (2016)

4. N. I. Vatin, N.B. Kolosova, I.A. Berdyugin, Construction of Unique Buildings and Structures, 4 (9) 30-35 (2013).

5. G.I. Abdullayev, Magazine of Civil Engineering, 2(20) 52-54 (2011)

6. A.E. Radchenko, M.V. Petrochenko, Construction of Unique Buildings and Structures, 1 (28), 87-95 (2015)

7. T.N. Soldatenko, Ye.S. Zalata, V.V. Bespalov, Construction of Unique Buildings and Structures, 2 (29), 67-75 (2015)

8. Yu.B. Kalugin. Magazine of Civil Engineering, 7, 70-80. doi: 10.5862/MCE.67.7 (2016)

9. I. S. Ptukhina, M. Ye. Vyatkin., T. A. Musorina, Construction of Unique Buildings and Structures, 8 (23), 57-64 (2014)

10. I.B. Azarova, Magazine of Civil Engineering, 7(59), 18-29 doi: 10.5862/MCE.59.2 (2015)

11. O.V. Chulgayeva, V.S. Chulgayeva, Magazine of Civil Engineering, 3, 61-64. (2009)

12. P.I. Gorelik, Construction of Unique Buildings and Structures, 12 (27), 91-99 (2014)

13. URL: https://www.gartner.com/it-glossary/enterprise-resource-planning-erp/

14. Leon, Alexis. Enterprise Resource Planning. New Dehli: McGraw-Hill, ISBN 978-007065680-2 (2008).

15. S. Hamilton, Maximizing your ERP system: a practical guide for managers. (McGrawHill,. ISBN 0-07-140611-5, 2003)

16. S. Nakamoto. Bitcoin: A Peer-to-Peer Electronic Cash System. (2008)

17. A. Mottaeva, A. Zheltenkov, E3S Web of Conferences 33, 01038 (2018) https://doi.org/10.1051/e3sconf/20183301038

18. I. Potekhin, V. Mischenko, A. Mottaeva, A. Zheltenkov, E3S Web of Conferences 33, 03020 (2018) https://doi.org/10.1051/e3sconf/20183303020 